\title{
Efficacy of RetroNectin-activated cytokine-induced killer cell therapy in the treatment of advanced hepatocelluar carcinoma
}

\author{
WEI LI $^{1 *}$, YAOMEI WANG ${ }^{2 *}$, DANIEL B. KELLNER ${ }^{3}$, LINGDI ZHAO $^{1}$, LINPING XU $^{4}$ and QUANLI GAO ${ }^{1}$ \\ ${ }^{1}$ Department of Immunotherapy, The Affiliated Cancer Hospital of Zhengzhou University, Henan Cancer Hospital, Zhengzhou, \\ Henan 450008; ${ }^{2}$ School of Life Sciences, Zhengzhou University, Zhengzhou, Henan 450001, P.R. China; \\ ${ }^{3}$ Department of Medicine, Weill Cornell Medical College, New York, NY 10065, USA; \\ ${ }^{4}$ Department of Research and Foreign Affairs, The Affiliated Cancer Hospital of Zhengzhou University, \\ Henan Cancer Hospital, Zhengzhou, Henan 450008, P.R. China
}

Received March 21, 2015; Accepted April 29, 2016

DOI: $10.3892 /$ ol.2016.4629

\begin{abstract}
The present study aimed to investigate the efficacy of RetroNectin-activated cytokine-induced killer cell (R-CIK) therapy in advanced hepatocellular carcinoma patients as compared with conventional chemotherapy, a comparison that has not yet been thoroughly studied. From January 2010 to October 2013, 74 patients with an initial diagnosis of advanced hepatocelluar carcinoma were enrolled in the study. Patients were assigned to one of two treatment arms: patients in arm 1 $(n=37)$ received $\mathrm{R}-\mathrm{CIK}$ treatment as the first line therapy, whereas those in $\operatorname{arm} 2(n=37)$ received chemotherapy as the first line treatment. The primary end point measured in this study was median overall survival (mOS). Median progression-free survival time (mPFS) and 1- and 2-year survival rates were recorded as secondary end points. Kaplan-Meier analysis was performed on all mOS and mPFS data, and treatment hazard ratios were established using the Cox proportional hazards model. The 1-year survival rate in treatment arm 1 was $42.47 \%$ vs. $24.89 \%$ in arm 2 (95\% CI, 24.91-59.01\% vs. $12.10-40.02 \%$, $\mathrm{P}=0.066)$; the 2-year survival rates were 21.24 and $5.53 \%(95 \%$ CI, 4.60-45.86 vs. $0.46-21.06 \%, \mathrm{P}=0.106)$ in arms 1 and 2 , respectively; the mPFS in arm 1 was 4.37 vs. $3.90\left(x^{2}=0.182\right.$, $\mathrm{P}=0.670$ ) in arm 2; and the mOS in arm 1 was 14.03 months vs. 9.46 months $\left(\mathrm{x}^{2}=4.406, \mathrm{P}=0.036\right)$ in arm 2. Calculations of univariate analyses of arm 1 , R-CIK cycles $\geq 6$, KPS $>70$, AFP $\leq 400 \mathrm{ng} / \mathrm{ml}$, and findings of no vascular invasion and no extra-hepatic metastasis were potential predictive factors
\end{abstract}

Correspondence to: Professor Quanli Gao, Department of Immunotherapy, The Affiliated Cancer Hospital of Zhengzhou University, Henan Cancer Hospital, 127 Dong Ming Road, Zhengzhou, Henan 450008, P.R. China

E-mail: gaoquanli1@aliyun.com

${ }^{*}$ Contributed equally

Key words: R-CIK, advanced hepatocelluar carcinoma, immunotherapy, chemotherapy
$(\mathrm{P}<0.05)$. Calculations from multivariate analyses similarly identified these factors as potentially having predictive value $(\mathrm{P}<0.05)$. The main adverse effects of R-CIK therapy included fever and headache pain. R-CIK treatment may prolong mOS in advanced hepatocellular carcinoma patients compared with conventional chemotherapy. Patients who underwent $\geq 6$ cycles of R-CIK, had KPS scores $>70$, AFP $\leq 400 \mathrm{ng} / \mathrm{ml}$, displayed no evidence of vascular invasion, and no extra-hepatic metastasis appeared to have longer survival times compared with other cohorts in the present study.

\section{Introduction}

Hepatocellular carcinoma (HCC), the most common of the hepatobiliary malignancies, ranks as the fifth most common type and the third primary cause associated with cancer mortality (1). Recent data indicates that the incidence of HCC appears to be increasing rapidly all over the world (2). Although the majority of cases are observed in developing nations, there is also evidence of a rising incidence of HCC in both North America and Europe $(3,4)$. Despite aggressive research, the prognosis for HCC patients remains relatively poor, and a definitive cure remains elusive, particularly in advanced cases.

At present, partial hepatectomy remains a potential curative treatment for most early-stage HCC patients (solitary tumor $\leq 5 \mathrm{~cm}$ in size, or $\leq 3$ tumors each $\leq 3 \mathrm{~cm}$ in size and no evidence of gross vascular invasion) (5-7). Although partial liver resection may achieve a 5-year survival rate of $\sim 50-70 \%$, $\mathrm{HCC}$ recurrence rates at 5 years have been reported to exceed $70 \%$ following such procedures (8-10). In addition, because of the limitations of preserved liver function, considerations of patient performance, and factors such as tumor size and position, $<30 \%$ patients are deemed suitable candidates for partial resection surgery (11). Liver transplantation is another potentially curative therapeutic option for patients with early-stage HCC. However, the shortage of donor organs and the numerous factors that complicate finding, acquiring, and successfully transplanting a well-matched liver severely restrict the use of transplantation as a treatment alternative $(5,12)$. In recent years, the techniques of local-regional ablation and embolization 
have provided additional local-regional treatment options for patients who are not suitable surgical candidates $(13,14)$. However these therapies are not adequate for patients with advanced HCC.

Sorafenib, an oral multi-kinase inhibitor that suppresses tumor cell proliferation and angiogenesis, has been shown to effectively improve outcomes in cases of advanced or metastatic HCC. However, the impact of this drug is quite limited, as the mOS of advanced or metastatic HCC patients on sorafenib is only 6.5-10.7 months $(15,16)$. Recently, the development of novel chemotherapy drugs such as Oxaliplatin, Capecitabine, and Gemcitabine among others has facilitated the development of systemic chemotherapy regimens for the treatment of HCC. However, this approach has so far only demonstrated modest improvements in outcomes, including an mOS of 6.47-12.2 months in the treatment of advanced HCC (17-19).

Because of the limitations of surgical and chemotherapeutic options, immunotherapy has gained steadily increasing attention as a treatment option for advanced HCC. In 1991, Schmidt-Wolf, IG et al identified a type of anti-tumor effector cells, known as cytokine-induced killer cells (CIK), that proliferate rapidly in vitro, possess strong antitumor activity against a broad spectrum of solid tumors, and cause minimal adverse effects when active in the host's body (20). As expected, the anti-tumor effect of CIK depends on the number of active CIK cells and on the overall functional quality of the cells, a factor that is particularly important when considering the techniques employed to culture CIK cells for therapeutic delivery. Recent studies have reported that RetroNectin can improve conglutination, extension, differentiation and proliferation of cultured cells, all of which contribute to more efficient stimulation of T cells (21-24). Our previous study also confirmed this (25). In the present study, the clinical effects of R-CIK therapy were compared with standard chemotherapy and the predictive factors governing the efficacy of R-CIK treatment were investigated in patients with advanced HCC.

\section{Materials and methods}

Patients. Between January 2010 and October 2013, 74 patients with an initial diagnosis of advanced hepatocelluar carcinoma (AJCC criteria) were enrolled in this study. Patients were assigned to either arm $1(n=37)$ to receive CIK treatment as a first line first line therapy, or arm $2(n=37)$ to receive chemotherapy [Oxaliplatin $\left(130 \mathrm{mg} / \mathrm{m}^{2}\right)$ combined with Capecitabine $\left.\left(1,000 \mathrm{mg} / \mathrm{m}^{2}\right)\right]$ as a first line treatment. The present study was approved by the Ethics Committee at The Affiliated Cancer Hospital of Zhengzhou University (Zhengzhou, China) and an approved consent form was signed by all the patients. For purposes of analysis, two subsets of HCC patients were identified. One subset consists of patients who had previously received local-regional treatments [e.g. transcatheter arterial chemoembolization (TACE), radiofrequencey ablation (RFA), surgery] for early HCC, but who had subsequently developed distant metastasis and/or multiple intra-hepatic metastases ( $>3$ nodules) that could not be effectively treated with local-regional treatments and where the patient could not reasonably be expected to pay the fee of sorafenib therapy. The other subset of patients identified had received no prior therapy and presented initially with distant metastasis and/or multiple intra-hepatic metastases ( $>3$ nodules) that could be effectively with local-regional treatments and for whom the fee of sorafenib therapy could not be paid. Both subsets of patients were included in the group considered to have advanced HCC and were enrolled in the study. The clinical characteristics of the 74 patients are detailed in Table I.

Study design and response. Patients were assigned to one of two treatment groups. Patients in arm 1 received R-CIK as a first line therapy, while patients in arm 2 received chemotherapies [Oxaliplatin $\left(130 \mathrm{mg} / \mathrm{m}^{2}\right)$ combined with Capecitabine $\left.\left(1,000 \mathrm{mg} / \mathrm{m}^{2}\right)\right]$. The primary endpoint of the study was mOS, and secondary endpoints were mPFS and 1- and 2-year survival rates. During treatment, patients received follow-up and reviews every 2 months to evaluate the changes in patients' conditions. The follow-up deadline was December 8, 2014. Responses to therapy were evaluated using RECIST 1.1 criteria (26). According to these criteria, clinical effects were divided into complete response (CR), partial response (PR), stable disease (SD) and progressive disease (PD). PFS was calculated from the first treatment to the time at which patients were found to meet the criteria for PD. OS was calculated from the time of their first treatment to the time of death or to the time the patient was re-censored at the last instance of contact with the live patient. Adverse reactions of these regimes were evaluated using the National Cancer Institute Common Toxicity Criteria 3.0 (NCI-CTC 3.0), accordingly, reactions were divided into grades 1-4 (27). In arm 1, when patients emerged as meeting the criteria for PD, R-CIK combined with chemotherapy (Oxaliplatin combined with Capecitabine) or R-CIK and/or best supportive care (BSC) was be applied to these patients; when patients were identified to meet the criteria for $C R / P R / S D$, R-CIK or BSC would be applied to these patients. However, in $\operatorname{arm} 2$, when patients met the criteria for PD, other chemotherapy methods and/or BSC would be applied to these patients; when patients in arm 2 were found to qualify as showing $\mathrm{CR} / \mathrm{PR} / \mathrm{SD}$, chemotherapy or BSC was continued. Details of the courses of therapy in the two treatment arms are shown in Fig. 1.

Preparation of $R$-CIK. The method used for CIK cell preparation in the present study was slightly different from methods detailed in previous literature $(25,28)$. Peripheral blood mononuclear cells (PBMCs) were collected from $50 \mathrm{ml}$ peripheral blood draws taken from patients. These cells were coated with RetroNectin $(10 \mu \mathrm{g} / \mathrm{ml}$; Takara Biomedical Technology Co., Ltd, Beijing, China) and anti-CD3 antibody $(5 \mu \mathrm{g} / \mathrm{ml}$; catalog no. 7381803; GE Healthcare Bio-Sciences, Pittsburgh, PA, USA) for $24 \mathrm{~h}$ and then cultured in GT-T551 medium (Takara Bio Inc., Otsu, Japan), which contained recombinant human interleukin-2 (rhIL-2; 1,000 U/ml), interferon- $\gamma$ (IFN- $\gamma ; 1,000 \mathrm{U} / \mathrm{ml}$ ) and $5 \%$ inactive autogeneic plasma, at $37^{\circ} \mathrm{C}$ with $5 \% \mathrm{CO}_{2}$ for 4 days. Then the cells were cultured with fresh IL-2 and $2 \%$ inactive autogeneic plasma-containing medium for 5 days. At day 15, R-CIKs were harvested and analyzed for phenotype. All the products were free of bacterial, mycoplasma, and fungal contamination. The endotoxin level was $<5 \mathrm{EU}$ in all samples.

Phenotypic assessment of R-CIK. R-CIKs $\left(1 \times 10^{6}\right)$ and PBMCs $\left(1 \times 10^{6}\right)$ were harvested and were double stained with $10 \mu 1$ 
Table I. Patient characteristics.

\begin{tabular}{|c|c|c|c|c|c|c|c|}
\hline Characteristic & Arm 1 & Arm 2 & $\mathrm{P}$ & Characteristic & Arm 1 & Arm 2 & $\mathrm{P}$ \\
\hline Number of patients & 37 & 37 & & $\operatorname{ALT}(\mathrm{U} / \mathrm{l})$ & & & 0.451 \\
\hline Age (years) & & & 0.227 & $>\mathrm{ULN}$ & 13 & 10 & \\
\hline$<60$ & 26 & 21 & & $\leq \mathrm{ULN}$ & 24 & 27 & \\
\hline$\geq 60$ & 11 & 16 & & AST (U/l) & & & 0.639 \\
\hline Gender & & & 0.207 & $>\mathrm{ULN}$ & 17 & 15 & \\
\hline Male & 29 & 33 & & $\leq \mathrm{ULN}$ & 20 & 22 & \\
\hline Female & 8 & 4 & & $\gamma$-GGT (U/l) & & & 0.632 \\
\hline Diameter of tumor $(\mathrm{cm})$ & & & 0.321 & $>\mathrm{ULN}$ & 24 & 22 & \\
\hline$\geq 5,<7$ & 10 & 14 & & $\leq \mathrm{ULN}$ & 13 & 15 & \\
\hline$>7$ & 27 & 23 & & PT (s) & & & 0.812 \\
\hline KPS (scores) & & & 0.227 & $>\mathrm{ULN}$ & 15 & 14 & \\
\hline$>70$ & 21 & 26 & & $\leq \mathrm{ULN}$ & 22 & 23 & \\
\hline$\leq 70$ & 16 & 11 & & $\operatorname{PLT}(/ 1)$ & & & 0.259 \\
\hline Child-Pugh & & & 0.075 & $>\mathrm{LLN}$ & 27 & 31 & \\
\hline $\mathrm{A}+\mathrm{B}$ & 27 & 33 & & $\leq \mathrm{LLN}$ & 10 & 6 & \\
\hline $\mathrm{C}$ & 10 & 4 & & Median R-CIK cycles & $5(3-24)$ & 0 & \\
\hline $\operatorname{AFP}(\mathrm{ng} / \mathrm{ml})$ & & & 0.480 & \multirow{4}{*}{\multicolumn{4}{|c|}{$\begin{array}{l}\text { KPS, Karnofsky; AFP, alpha-fetal protein; TACE, transarterial che- } \\
\text { moembolization; RFA, radiofrequency ablation; ULN, upper limit } \\
\text { of normal; ALT, alanine transaminase; AST, aspartate transaminase; } \\
\gamma \text {-GGT, gamma glutamyl transpeptidase; PT, prothrombin time; PLT, } \\
\text { platelet; LLN, lower limit of normal. }\end{array}$}} \\
\hline$>400$ & 20 & 23 & & & & & \\
\hline$\leq 400$ & 17 & 14 & & & & & \\
\hline $\begin{array}{l}\text { Hepatitis B } \\
\text { Yes }\end{array}$ & 31 & 20 & 0.553 & & & & \\
\hline
\end{tabular}

Vascular invasion

Yes

6

8

No

Cirrhosis

Yes

21

24

No

25

7

Extrahepatic metastasis

Yes

No

Ascites

Yes

10

No

27

Once TACE

Yes

Once RFA

Yes

No

Once surgery

Yes

No

Albumin (g/l)

$<35$

$\geq 35$

Bilirubin $(\mu \mathrm{mol} / \mathrm{l})$

$$
>\mathrm{ULN}
$$

0.566

Table I. Continued.

KPS, Karnofsky; AFP, alpha-fetal protein; TACE, transarterial chemoembolization; RFA, radiofrequency ablation; ULN, upper limit $\gamma$-GGT, gamma glutamyl transpeptidase; PT, prothrombin time; PLT, platelet; LLN, lower limit of normal.

fluorescein isothiocyanate (FITC) CD3 (catalog no., 555342) and phycoerythrin (PE) CD4 (catalog no., 555347), CD8 0.183 (catalog no., 555635), CD16 (catalog no., 555408) and CD56 (catalog no., 555517) (BD Biosciences, San Jose, CA, USA), all at a 1:200 dilution. Samples were incubated at $4^{\circ} \mathrm{C}$ for $30 \mathrm{~min}$, then washed twice with PBS and re-suspended in $500 \mathrm{ml}$ PBS. (BD Biosciences) and data on 10,000 cells were acquired and analyzed. Propidium iodide and annexin V-FITC (BD Biosciences) were used to measure viability and apoptosis, according to the manufacturer's protocol.

0.344

Cytotoxicity assessment of R-CIK. At the end of cell expansion, R-CIKs' anti-tumor activity was tested using an overnight cytotoxicity assay with K-562 (chronic myeloid leukaemia) cell line cells used as targets. The cytotoxic activity of cells was investigated in a lactate dehydrogenase $(\mathrm{LDH})$ release assay. This non-radioactive assay is a colorimetric alternative to the ${ }^{51} \mathrm{Cr}$ release assay and quantitatively measures LDH that is released upon cell lysis in the same way that ${ }^{51} \mathrm{Cr}$ is released. Every experiment, at each effector cell concentration, was performed in a triplicate set of wells and, the mean value was calculated.

0.782

Statistical analysis. SPSS software, version 17.0(SPSS, Inc., Chicago, IL, USA) was used to perform the statistical analysis.

0.483 Data for phenotypic analysis of R-CIK cells and cytotoxicity were analyzed by independent sample $t$-tests. For survival time analysis, the Kaplan-Meier method was used. Prognostic factors of survival time were analyzed using log-rank test and
0.480 Fluorescence was detected by FACS Calibur flow cytometer 


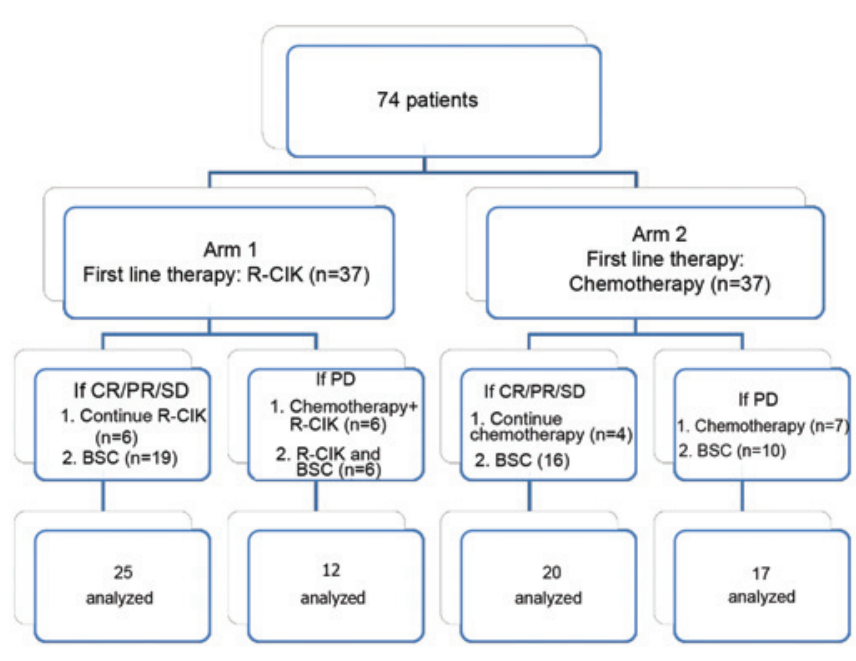

Figure 1. Flow chart describing patient allocation into treatment groups. Patients were assigned to two treatment groups: arm 1 and arm 2. R-CIK, RetroNectin-activated cytokine-induced killer cell; CR, complete remission; $\mathrm{PR}$, partial remission; SD, stable disease; BSD, best standard care; PD, progressive disease.

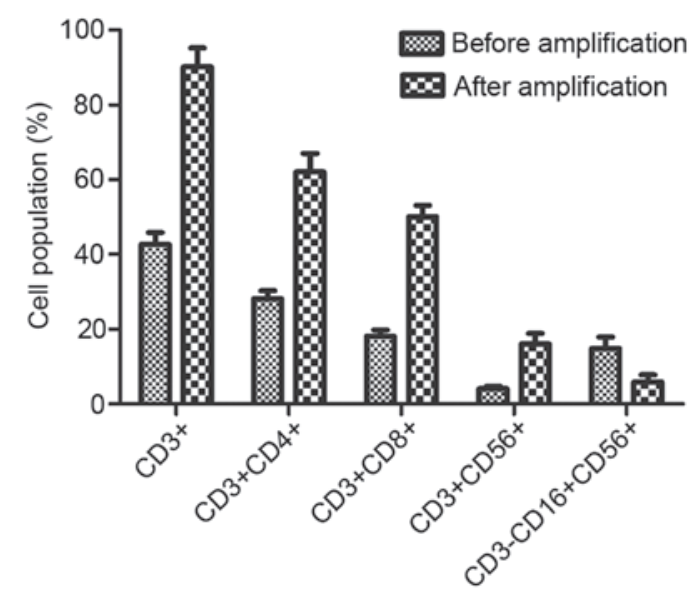

Figure 2. Phenotype of peripheral blood mononuclear cells and RetroNectin-activated cytokine-induced killer cell therapy.

multivariable analysis. For all data, $\mathrm{P}<0.05$ was considered to indicate a statistically significant difference.

\section{Results}

Phenotypic analysis of $R$-CIKs. Phenotypic analysis of $\mathrm{R}-\mathrm{CIKs}$ in the patients prior to culture and after 15 days of culture indicated that the percentages of $\mathrm{CD} 3+, \mathrm{CD} 3+/ \mathrm{CD} 4+$, CD3+/CD8+ and CD3+/CD56+, increased from 42.67 \pm 3.21 , $28.12 \pm 2.16,18.13 \pm 1.66$ and $4.12 \pm 0.56 \%$ to $90.21 \pm 5.02$, $62.01 \pm 5.01,50.13 \pm 3.03$ and $24.03 \pm 2.81 \%$ respectively, (all $\mathrm{P}<0.05)$. In contrast, the population of CD3-/CD16+/CD56+ cells reduced from $14.87 \pm 2.99$ to $5.89 \pm 1.87 \%(\mathrm{P}<0.05)$. The details are presented in Fig. 2.

Cytotoxicity of $R$-CIK in vitro. A sample of each R-CIK expansion obtained from a total of 37 patients was tested for cytotoxicity against K-562, an NK-sensitive leukemia target cell line. At effector to target (E/T) cell ratios of 40:1, 20:1

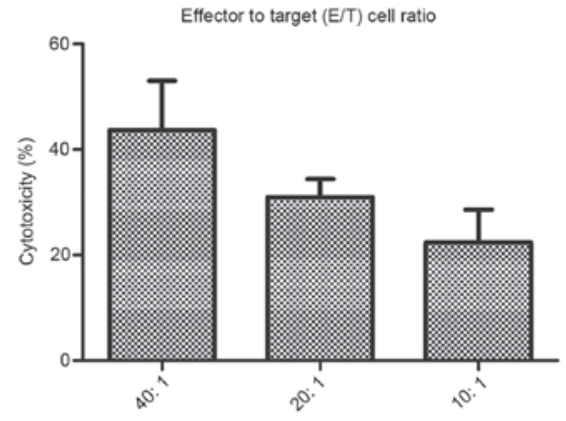

Figure 3. Mean RetroNectin-activated cytokine-induced killer cell cytotoxity for K-562 cell line.

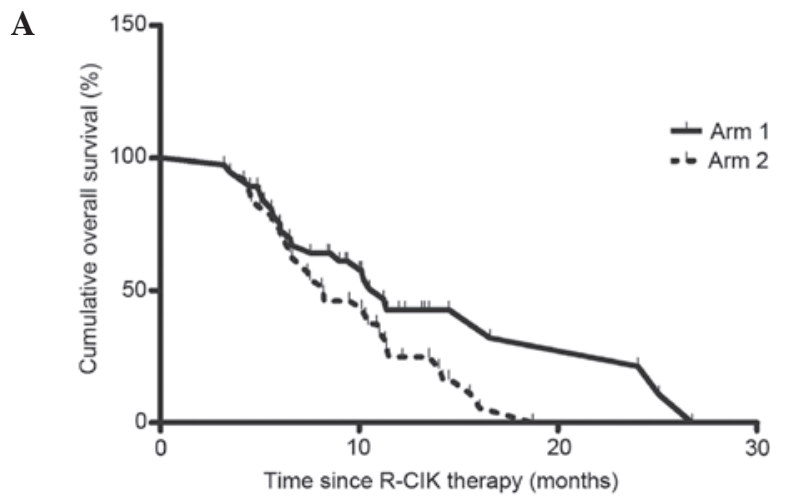

B

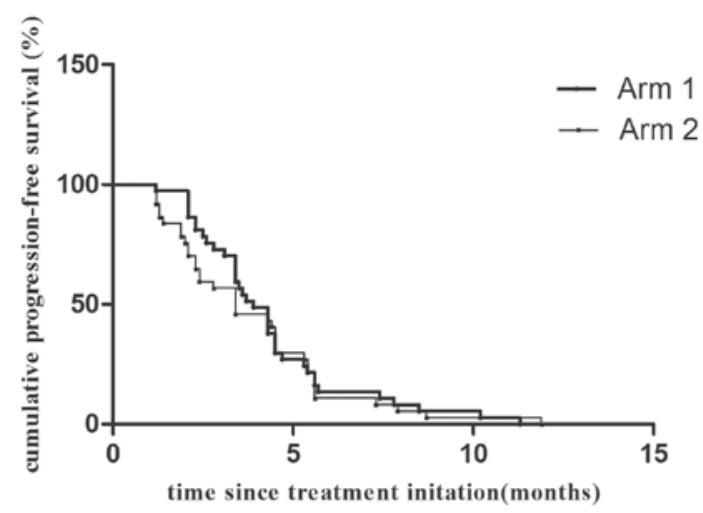

Figure 4. (A) Overall survival of patients in arm 1 and arm 2. (B) Progression free survival of patients in arm 1 and arm 2. R-CIK, RetroNectin-activated cytokine-induced killer cell.

and 10:1 the median levels of cytotoxicity were $43.66 \pm 9.36 \%$, $30.95 \pm 3.49 \%$ and $22.39 \pm 6.24 \%$, respectively. The details are presented in Fig. 3.

Treatment outcomes. Follow-up with all patients occurred from January 2010 to October 2013, the outcomes observed in arm 1 patients were significantly improved compared with the outcomes in arm 2 patients. Specially, the mOS of arm 1 vs. arm 2 was 14.03 vs. 9.46 months $\left(\chi^{2}=4.406 \mathrm{P}=0.036\right)$ (Fig. 4A). The 1-year survival rate was 42.47 vs. $24.89 \%$ (95\% CI $24.91-59.01 \%$ vs. $12.10-40.02 \%, \mathrm{P}=0.066$ ), the 2 -year survival rate was 21.24 vs. $5.53 \%$ (95\% CI $4.60-45.86 \%$ vs. $0.46-21.06 \%, \mathrm{P}=0.106)$, and the $\mathrm{mPFS}$ of arm 1 vs. arm 2 was 4.37 vs. $3.90\left(\mathrm{x}^{2}=0.182 \mathrm{P}=0.670\right)(\mathrm{Fig} 4 \mathrm{~B})$, indicating no significant differences in these measures. Although the mPFS, 
A

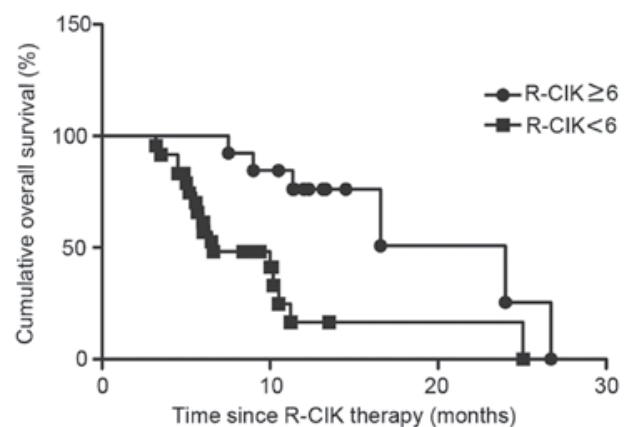

B

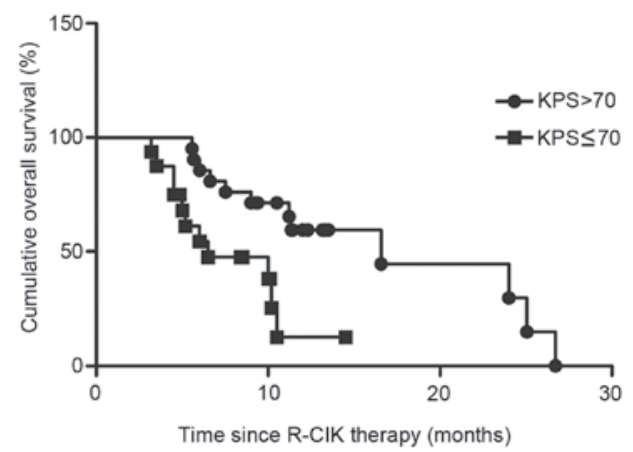

C

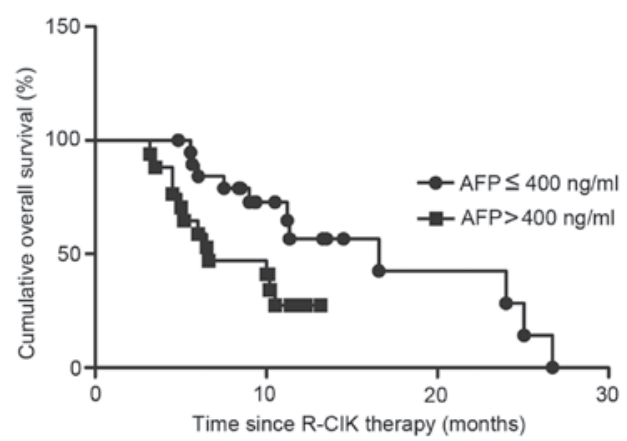

D

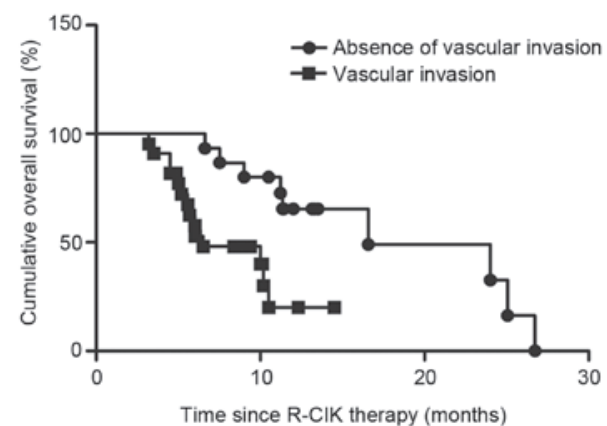

$\mathbf{E}$

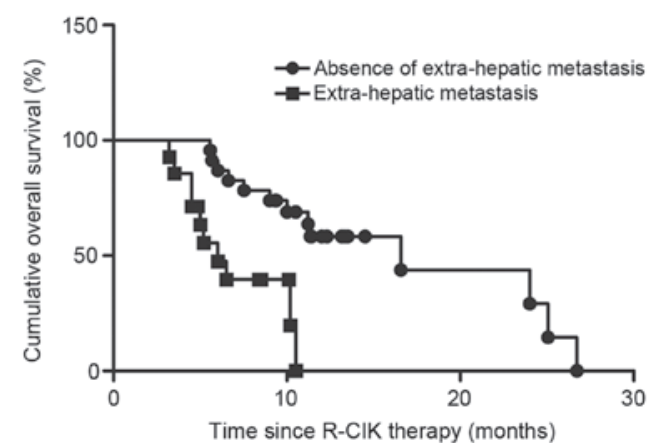

Figure 5. (A) OS of patients in arm 1 based on R-CIK cycles; (B) OS of patients in arm 1 based on KPS scores; (C) OS of patients in armlbased on AFP; (D) OS of patients in arm 1 based on vascular invasion or not; (E) OS of patients in arm 1 based on extra-hepatic metastasis or not. R-CIK, RetroNectin-activated cytokine-induced killer cell; OS, overall survival; AFP, alpha-feto protein; KPS, Karnofsky.
Table II. Univariate analysis.

\begin{tabular}{lcccc}
\hline Variable & $\begin{array}{c}\text { Median OS } \\
\text { (months) }\end{array}$ & $\mathrm{P}$ & $\begin{array}{c}\text { Median PFS } \\
\text { (months) }\end{array}$ & $\mathrm{P}$ \\
\hline Age (years) & & 0.697 & & 0.468 \\
$\quad<60$ & 13.674 & & 4.546 & \\
$\geq 60$ & 10.269 & & 3.955 & \\
Gender & & 0.605 & & 0.517 \\
$\quad$ Male & 14.440 & & 4.507 & \\
$\quad$ Female & 9.390 & & 3.875 & \\
Diameter of tumor & & 0.406 & & 0.508
\end{tabular}

(cm)

$\begin{array}{lll}\geq 5,<7 & 14.086 & 4.760 \\ >7 & 11.244 & 4.226\end{array}$

KPS (scores)

0.004

0.401

$>70$

17.014

7.964

4.638

4.019

Child-Pugh

0.145

0.339

$\mathrm{A}+\mathrm{B}$

15.057

4.578

$\mathrm{C}$

8.151

3.810

AFP (ng/ml)

$>400$

8.270

0.026

0.125

$\leq 400$

16.768

3.763

4.833

Hepatitis B

Yes

13.327

0.991

0.961

No

13.868

4.217

4.400

Vascular invasion

Cirrhosis

Extrahepatic metastasis

Ascites

Once TACE

Once RFA

Once surgery

Albumin (g/l)
0.004

Yes

8.423

No

18.300

4.055

4.833

0.283

8.762

14.781

3.943

No

4.470

Yes

7.030

16.928

3.657

4.804

0.979

0.508

Yes

9.878

4.226

No

14.064

4.760

0.731

0.263

14.452

4.745

No

10.142

3.929

0.720

0.331

13.543

.100

No

11.943

4.169

0.258

0.227

16.149

5.033

No

11.215

4.052

0.605

0.304

0.669

0.116

$<35$

4.444 
Table II. Continued.

\begin{tabular}{|c|c|c|c|c|}
\hline Variable & $\begin{array}{l}\text { Median OS } \\
\text { (months) }\end{array}$ & $\mathrm{P}$ & $\begin{array}{c}\text { Median PFS } \\
\text { (months) }\end{array}$ & $\mathrm{P}$ \\
\hline Bilirubin $(\mu \mathrm{mol} / \mathrm{l})$ & & 0.792 & & 0.396 \\
\hline$>\mathrm{ULN}$ & 10.553 & & 4.100 & \\
\hline$\leq \mathrm{ULN}$ & 13.571 & & 4.656 & \\
\hline $\operatorname{ALT}(\mathrm{U} / \mathrm{L})$ & & 0.283 & & 0.355 \\
\hline$>\mathrm{ULN}$ & 11.271 & & 4.113 & \\
\hline$\leq \mathrm{ULN}$ & 16.081 & & 4.846 & \\
\hline AST (U/L) & & 0.625 & & 0.310 \\
\hline$>\mathrm{ULN}$ & 10.681 & & 4.070 & \\
\hline$\leq \mathrm{ULN}$ & 13.161 & & 4.724 & \\
\hline$\gamma$-GGT (U/L) & & 0.787 & & 0.238 \\
\hline$>\mathrm{ULN}$ & 13.743 & & 3.846 & \\
\hline$\leq \mathrm{ULN}$ & 10.104 & & 4.654 & \\
\hline PT (s) & & 0.620 & & 0.404 \\
\hline$>$ ULN & 10.636 & & 4.136 & \\
\hline$\leq \mathrm{ULN}$ & 13.027 & & 4.713 & \\
\hline PLT (/L) & & 0.238 & & 0.657 \\
\hline$>$ LLN & 17.092 & & 4.481 & \\
\hline$\leq \mathrm{LLN}$ & 12.913 & & 4.070 & \\
\hline R-CIK cycles & & 0.002 & & 0.154 \\
\hline$\geq 6$ & 19.317 & & 5.077 & \\
\hline$<6$ & 10.173 & & 3.988 & \\
\hline
\end{tabular}

KPS, Karnofsky; AFP, alpha-fetal protein; TACE, transarterial chemoembolization; RFA, radiofrequency ablation; ULN, upper limit of normal; ALT, alanine transaminase; AST, aspartate transaminase; $\gamma$-GGT, gamma glutamyl transpeptidase; PT, prothrombin time; PLT, platelet; LLN, lower limit of normal.

1-year survival rates, and 2-year survival rates demonstrated no significant differences between the two treatment arms, the mOS of arm 1 was significantly prolonged when compared with arm 2 . Therefore, patients with advanced HCC who could not receive local-regional treatments benefited significantly from R-CIK treatment.

Prognosis factors of $R$-CIK treatment based on mOS. Univariate analyses of arm 1 revealed that receiving $\geq 6$ cycles of R-CIK (Fig. 5A), a KPS $>70$ (Fig. 5B), AFP $\leq 400 \mathrm{ng} / \mathrm{ml}$ (Fig. 5C), absence of vascular invasion (Fig. 5D), and absence of extra-hepatic metastasis (Fig. 5E) were all potential predictive factors $(\mathrm{P}<0.05)$, (Table II). Multivariate analyses similarly identified these factors as potentially predictive $(\mathrm{P}<0.05)$ (Table III).

Adverse events. The incidences of adverse treatment effects are described in Table IV. None of the patients in arm 1 failed to complete immunotherapy or were ruled out because of side effects. No severe adverse effects (grade 3 or 4) were associated with R-CIK therapy. Common side effects of immunotherapy (grade 1 or 2) included fever and headache pain. None of the patients in arm 2 failed to complete chemotherapy or were ruled out because of side effects. Common side effects of chemotherapy (grade 1 or 2) included nausea, leukopenia, thrombocytopenia and liver dysfunction. There were 4 patients that developed grade 3 or 4 side effects: Two patients developed fevers and two were found to have leukopenia.

\section{Discussion}

At present, advanced HCCs are not sufficiently treated with traditional chemotherapy or radiotherapy. And while local-regional treatments may be appropriate for cases of early HCC, they are not suitable for patients with advanced HCC. Fortunately, recent developments in immunology have given researchers and clinical physicians the option of utilizing immunotherapy as a significant component of cancer treatment (29).

CIK cell therapy is emerging as an important form of adoptive immunotherapy thanks to its high amplification efficiency and strong anti-tumor activity. CIK cell therapy represents a realistic novel option in the field of cancer therapy as it consistently demonstrates strong anti-tumor activity and improves the overall survival time of cancer patients when used alone, or when combined with other conventional therapies. Since 1991, CIK cell therapy has been evaluated as an adoptive immunotherapy for cancer patients in a number of clinical trials, including in patients with HCC (28,30-33). For example, Pan et al (34) reported that CIK cell treatment as an adjuvant therapy for postoperative hepatocellular carcinoma patients could increase overall survival rates compared with surgery alone. Similarly, Yu et al (31) reported that adding CIK treatment could prolong the overall survival time and progression-free survival time of HCC patients found to be unsuitable for surgical treatment in 2014. In 2015, Lee et al reported (35) that adjuvant immunotherapy with CIK cells increased recurrence-free and overall survival combined with surgical resection, radiofrequency ablation, and percutaneous ethanol injection in a multi-center, randomized, open-label, phase 3 trial. These reports indicate that CIK cell immunotherapy has significant potential benefits for cancer patients. However, the specific question of whether CIK cell therapy can improve survival time of patients with advanced HCC remained unclear.

The effectiveness of CIK cell therapy depends on the quality and quantity of CIK cells obtained for therapeutic administration. In the CIK cell preparations in the present study, the method of culture was slightly different from methods employed in previous literature and it was possible to obtain more of the CD3+/CD56+ cellular subset on day 15 than common CIK cells preparation methods achieve (28). RetroNectin (RN) was added to the culture media in our CIK cell preparation (called R-CIK), which improves the conglutination, extension, and differentiation of these cells (25). Our results indicate that the percentages of $\mathrm{CD} 3+$, CD3+/CD4+, CD3+/CD8+ and CD3+/CD56+ cells were significantly increased after stimulation and expansion in culture (25). In addition, there was a significant decrease in the CD3-/CD16+/CD56+ population. It is widely accepted that the increase in CD4+ and CD8+ T cells during CIK expansion is crucial to tumor immunity. CD3+/CD56+ cells, which comprise a rare population of cells in normal peripheral 
Table III. Multivariate analysis.

\begin{tabular}{lccr}
\hline Parameters & Hazard ratio & 95\% confidence interval & P-value \\
\hline R-CIK ( $\geq 6$ cycles vs. 6 cycles) & 0.224 & $0.079-0.632$ & 0.005 \\
AFP (ng/ml) ( $>400$ vs. $\leq 400)$ & 0.363 & $0.142-0.924$ & 0.034 \\
KPS (>70 scores vs. $\leq 70$ scores) & 0.265 & $0.102-0.687$ & 0.006 \\
Vascular invasion (yes vs. no) & 0.227 & $0.078-0.661$ & 0.007 \\
Extrahepatic metastasis (yes vs. no) & 0.201 & $0.074-0.546$ & 0.002
\end{tabular}

R-CIK, RetroNectin-activated cytokine-induced killer cell; OS, overall survival; AFP, alpha-feto protein; KPS, Karnofsky.

Table IV. Adverse events distribution.

\begin{tabular}{|c|c|c|c|c|}
\hline \multirow[b]{2}{*}{ Side effects } & \multicolumn{2}{|c|}{ Arm 1} & \multicolumn{2}{|c|}{ Arm 2} \\
\hline & Grade 1/2 & Grade 3/4 & Grade $1 / 2$ & Grade 3/4 \\
\hline Fever & 15 & 0 & 8 & 2 \\
\hline Headache pain & 8 & 0 & 7 & 0 \\
\hline Nausea & 5 & 0 & 15 & 0 \\
\hline Leukopenia & 30 & 0 & 33 & 2 \\
\hline Liver dysfunction & 20 & 0 & 25 & 0 \\
\hline Diarrhea & 2 & 0 & 4 & 0 \\
\hline Thrombocytopenia & 10 & 0 & 7 & 0 \\
\hline Anemia & 5 & 0 & 7 & 0 \\
\hline
\end{tabular}

blood, are also significantly increased after stimulation and expansion. These may be the most important cells for the anti-cancer effect of CIK treatment (36) as they have shown strong anti-cancer activity in a variety of malignant tumor cell lines in vitro $(20,25,37)$. Therefore, we have good reason to hypothesize that our improved methods have allowed us to obtain R-CIK cells with particularly strong anti-tumor activity for transferring them to patients.

Although the present study failed to show a significant difference in mPFS between the two treatment arms, R-CIK treatment did significantly prolonged the mOS of advanced HCC patients compared with the chemotherapy arm. In the calculations from univariate analyses of arm 1, R-CIK cycles $\geq 6$, KPS $>70$, AFP $\approx \leq 400 \mathrm{ng} / \mathrm{ml}$, the absence of vascular invasion and a lack of extra-hepatic metastasis were all potential predictive factors $(\mathrm{P}<0.05)$. In the calculations from multivariate analyses, these factors were also found to have potential predictive value $(\mathrm{P}<0.05)$. These results indicate that the likely effects of R-CIK treatment can be reasonably well predicted based on preliminary laboratory tests and imaging reports.

In conclusion, the present study indicated R-CIK cell therapy can improve prognosis in advanced HCC and increasing the number of cycles of R-CIK cell therapy is likely to result in additional benefits. Discrepancies versus previous studies of CIK therapy may be attributed to the differences in stimulation and expansion methods, genetic and environmental backgrounds, staging systems, and sample size. It will certainly be necessary to carry out numerous additional studies in order to optimize techniques and determine the full range of application for this type of therapy. At the same time, the combination of R-CIK with conventional chemotherapy, as well as R-CIK combined with Sorafenib also clearly merit exploration.

R-CIK treatment can prolong mOS of advanced hepatocellular carcinoma patients compared with conventional chemotherapy alone. Patients who undergo $>6$ cycles of R-CIK, have a KPS $>70$, an AFP $\leq 400 \mathrm{ng} / \mathrm{ml}$, no vascular invasion and no extra-hepatic metastases may have longer survival times in comparison with other patients.

\section{Acknowledgements}

The authors are grateful for the collaboration received from the participating college and its staff and Dr Weiquan Lu and Dr Erjiang Zhao from the Department of Cancer Prevention, Henan Cancer Hospital, China, for statistical analysis. Professor Quanli Gao designed this study, Dr Wei Li and Dr Yaomei Wang wrote the paper, Dr Lingdi Zhao and Dr Linping $\mathrm{Xu}$ did the follow-up of all patients and Dr Daniel B. Kellner edited this paper as a native English speaker.

\section{References}

1. Qiang L, Huikai L, Butt K, Wang PP and Hao X: Factors associated with disease survival after surgical resection in Chinese patients with hepatocellular carcinoma. World J Surg 30: 439-445, 2006. 
2. Bosch FX, Ribes J and Borràs J: Epidemiology of primary liver cancer. Semin Liver Dis 19: 271-285, 1999.

3. El-Serag HB and Mason AC: Rising incidence of hepatocellular carcinoma in the United States. N Engl J Med 340: 745-750, 1999.

4. Taylor-Robinson SD, Foster GR, Arora S, Hargreaves S and Thomas HC: Increase in primary liver cancer in the UK, 1979-94. Lancet 350: 1142-1143, 1997.

5. Jarnagin WR: Management of small hepatocellular carcinoma: A review of transplantation, resection, and ablation. Ann Surg Oncol 17: 1226-1233, 2010.

6. Page AJ, Cosgrove DC, Philosophe B and Pawlik TM: Hepatocellular carcinoma: Diagnosis, management, and prognosis. Surg Oncol Clin N Am 23: 289-311, 2014.

7. Truty MJ and Vauthey JN: Surgical resection of high-risk hepatocellular carcinoma: Patient selection, preoperative considerations, and operative technique. Ann Surg Oncol 17: 1219-1225, 2010.

8. Asham EH, Kaseb A and Ghobrial RM: Management of hepatocellular carcinoma. Surg Clin North Am 93: 1423-1450, 2013.

9. Chok KS, Ng KK, Poon RT, Lo CM and Fan ST: Impact of postoperative complications on long-term outcome of curative resection for hepatocellular carcinoma. Br J Surg 96: 81-87, 2009.

10. Seo DD, Lee HC, Jang MK, Min HJ, Kim KM, Lim YS Chung YH, Lee YS, Suh DJ, Ko GY, et al: Preoperative portal vein embolization and surgical resection in patients with hepatocellular carcinoma and small future liver remnant volume: Comparison with transarterial chemoembolization. Ann Surg Oncol 14: 3501-3509, 2007.

11. Ikai I, Itai Y, Okita K, Omata M, Kojiro M, Kobayashi K, Nakanuma Y, Futagawa S, Makuuchi M and Yamaoka Y: Report of the 15th follow-up survey of primary liver cancer. Hepatol Res 28: 21-29, 2004.

12. Deans C and Leslie P: Hepatocellular carcinoma. Lancet 354 253-254, 1999.

13. Ribero D, Curley SA, Imamura H, Madoff DC, Nagorney DM Ng KK, Donadon M, Vilgrain V, Torzilli G, Roh M and Vauthey JN: Selection for resection of hepatocellular carcinoma and surgical strategy: Indications for resection, evaluation of liver function, portal vein embolization, and resection. Ann Surg Oncol 15: 986-992, 2008.

14. Vivarelli M, Guglielmi A, Ruzzenente A, Cucchetti A, Bellusci R, Cordiano C and Cavallari A: Surgical resection versus percutaneous radiofrequency ablation in the treatment of hepatocellular carcinoma on cirrhotic liver. Ann Surg 240: 102-107, 2004.

15. Bruix J, Raoul JL, Sherman M, Mazzaferro V, Bolondi L, Craxi A, Galle PR, Santoro A, Beaugrand M, Sangiovanni A, et al: Efficacy and safety of sorafenib in patients with advanced hepatocellular carcinoma: Subanalyses of a phase III trial. J Hepatol 57: 821-829, 2012.

16. Cheng AL, Kang YK, Chen Z, Tsao CJ, Qin S, Kim JS, Luo R, Feng J, Ye S, Yang TS, et al: Efficacy and safety of sorafenib in patients in the Asia-Pacific region with advanced hepatocellular carcinoma: A phase III randomised, double-blind, placebo-controlled trial. Lancet Oncol 10: 25-34, 2009.

17. Qin S, Bai Y, Lim HY, Thongprasert S, Chao Y, Fan J, Yang TS, Bhudhisawasdi V, Kang WK, Zhou Y, et al: Randomized, multicenter, open-label study of oxaliplatin plus fluorouracil/leucovorin versus doxorubicin as palliative chemotherapy in patients with advanced hepatocellular carcinoma from Asia. J Clin Oncol 31: 3501-3508, 2013.

18. von Delius S, Lersch C, Mayr M, Stock K, Schulte-Frohlinde E, Schmid RM and Eckel F: Capecitabine for treatment of advanced hepatocellular carcinoma. Hepatogastroenterology 54: 2310-2314, 2007

19. Zaanan A, Williet N, Hebbar M, Dabakuyo TS, Fartoux L, Mansourbakht T, Dubreuil O, Rosmorduc O, Cattan S, Bonnetain F, et al: Gemcitabine plus oxaliplatin in advanced hepatocellular carcinoma: A large multicenter AGEO study. J Hepatol 58: 81-88, 2013.

20. Schmidt-Wolf IG, Negrin RS, Kiem HP, Blume KG and Weissman IL: Use of a SCID mouse/human lymphoma model to evaluate cytokine-induced killer cells with potent antitumor cell activity. J Exp Med 174: 139-149, 1991.
21. Ma H, Zhang Y, Wang Q, Li Y, He J, Wang H, Sun J, Pan K, Chen $\mathrm{M}$ and Xia J: Therapeutic safety and effects of adjuvant autologous RetroNectin activated killer cell immunotherapy for patients with primary hepatocellular carcinoma after radiofrequency ablation. Cancer Biol Ther 9: 903-907, 2010.

22. Lee HJ, Lee YS, Kim HS, Kim YK, Kim JH, Jeon SH, Lee HW, Kim S, Miyoshi H, Chung HM and Kim DK: Retronectin enhances lentivirus-mediated gene delivery into hematopoietic progenitor cells. Biologicals 37: 203-209, 2009.

23. Lamers CH, van Elzakker P, van Steenbergen SC, Sleijfer S, Debets R and Gratama JW: Retronectin-assisted retroviral transduction of primary human T lymphocytes under good manufacturing practice conditions: Tissue culture bag critically determines cell yield. Cytotherapy 10: 406-416, 2008.

24. Yu SS, Nukaya I, Enoki T, Chatani E, Kato A, Goto Y, Dan K, Sasaki M, Tomita $\mathrm{K}$, Tanabe $\mathrm{M}$, et al: In vivo persistence of genetically modified $\mathrm{T}$ cells generated ex vivo using the fibronectin $\mathrm{CH} 296$ stimulation method. Cancer Gene Ther 15: 508-516, 2008

25. Wang Z, Zhang Y, Liu Y, Wang L, Zhao L, Yang T, He C, Song Y and Gao Q: Association of myeloid-derived suppressor cells and efficacy of cytokine-induced killer cell immunotherapy in metastatic renal cell carcinoma patients. J Immunother 37: 43-50, 2014

26. Watanabe H, Okada M, Kaji Y, Satouchi M, Sato Y, Yamabe Y, Onaya H, Endo M, Sone M and Arai Y: New response evaluation criteria in solid tumours-revised RECIST guideline (version 1.1). Gan To Kagaku Ryoho 36: 2495-2501, 2009 (In Japanese).

27. Trotti A, Colevas AD, Setser A, Rusch V, Jaques D, Budach V, Langer C, Murphy B, Cumberlin R, Coleman CN and Rubin P: CTCAE v3.0: Development of a comprehensive grading system for the adverse effects of cancer treatment. Semin Radiat Oncol 13: 176-181, 2003.

28. Liu L, Zhang W, Qi X, Li H, Yu J, Wei S, Hao X and Ren X: Randomized study of autologous cytokine-induced killer cell immunotherapy in metastatic renal carcinoma. Clin Cancer Res 18: 1751-1759, 2012

29. DeVita VJ Jr and Rosenberg SA: Two hundred years of cancer research. N Engl J Med 366: 2207-2214, 2012.

30. Hontscha C, Borck Y, Zhou H, Messmer D and Schmidt-Wolf IG: Clinical trials on CIK cells: First report of the international registry on CIK cells (IRCC). J Cancer Res Clin Oncol 137: 305-310, 2011.

31. Yu X, Zhao H, Liu L, Cao S, Ren B, Zhang N, An X, Yu J, $\mathrm{Li} \mathrm{H}$ and Ren X: A randomized phase II study of autologous cytokine-induced killer cells in treatment of hepatocelluar carcinoma. J Clin Immunol 34: 194-203, 2014.

32. Hui D, Qiang L, Jian W, Ti Z and Da-Lu K: A randomized, controlled trial of postoperative adjuvant cytokine-induced killer cells immunotherapy after radical resection of hepatocellular carcinoma. Dig Liver Dis 41: 36-41, 2009.

33. Shi M, Zhang B, Tang ZR, Lei ZY, Wang HF, Feng YY, Fan ZP, $\mathrm{Xu}$ DP and Wang FS: Autologous cytokine-induced killer cell therapy in clinical trial phase I is safe in patients with primary hepatocellular carcinoma. World J Gastroenterol 10: 1146-1151, 2004.

34. Pan K, Li YQ, Wang W, Xu L, Zhang YJ, Zheng HX, Zhao JJ, Qiu HJ, Weng DS, Li JJ, et al: The efficacy of cytokine-induced killer cell infusion as an adjuvant therapy for postoperative hepatocellular carcinoma patients. Ann Surg Oncol 20: 4305-4311, 2013.

35. Lee JH, Lee JH, Lim YS, Yeon JE, Song TJ, Yu SJ, Gwak GY, Kim KM, Kim YJ, Lee JW and Yoon JH: Adjuvant immunotherapy with autologous cytokine-induced killer cells for hepatocellular carcinoma. Gastroenterology 148: 1383-1391.e6, 2015.

36. Lu PH and Negrin RS: A novel population of expanded human CD3+CD56+ cells derived from T cells with potent in vivo antitumor activity in mice with severe combined immunodeficiency. J Immunol 153: 1687-1696, 1994.

37. Shablak A, Hawkins RE, Rothwell DG and Elkord E: T cell-based immunotherapy of metastatic renal cell carcinoma: Modest success and future perspective. Clin Cancer Res 15: 6503-6510, 2009. 